\title{
Impact of Soil Type and Compaction Conditions on Soil Water Characteristic
}

\author{
C. J. Miller, M.ASCE ; N. Yesiller, A.M.ASCE ; K. Yaldo ; and S. Merayyan
}

\begin{abstract}
Tests were conducted to determine the variation of water content and pore water suction for compacted clayey soils. The soils had varying amounts of clay fraction with plasticities ranging from low to high plasticity. The unsaturated soil behavior was investigated for six conditions, covering a range of compactive efforts and water contents. The experimental data were fit to four commonly used models for the water content-pore water suction relationship. Each model provided a satisfactory fit to the experimental data. However, the individual parameters obtained from the curve fits varied significantly between models. The soil water characteristic curves (SWCCs) were more sensitive to changes in compaction effort than changes in compaction water content. At similar water contents, the pore water suction increased with increasing compaction effort for each compaction condition and soil type. For all compaction conditions, the lowest plasticity soils retained the smallest water content and the highest plasticity soils retained the highest water content at a specified suction. In addition, SWCCs for soils compacted in the laboratory and in the field were similar.
\end{abstract}

\section{Introduction}

Compacted clay soils are commonly used as barrier materials in waste containment facilities. The selection of these soils as barrier materials is based on their saturated behavior, in particular the saturated hydraulic conductivity. In design, operation, and maintenance of landfills and other waste containment facilities, it is generally assumed that the clay is saturated during the entire life of the facility. In reality, the as-compacted clay is unsaturated and does not necessarily become saturated. This is particularly true for cover liner systems. Unsaturated properties and behavior of compacted clay soils must be well understood and quantified for better prediction of the performance of the soil as a barrier material.

The relationship between pore water suction and water content, as presented in a soil water characteristic curve (SWCC), is one of the fundamental relationships used to describe unsaturated behavior of a soil. Suction is inversely proportional to the water content in a soil. Suctions generally increase as the soil desaturates. Increasing suctions generally result in high resistance to flow and increases in effective stress. Desiccation cracking is a by-product of the increased effective stress.

In this study, soil water characteristic curves were developed for four compacted clay soils. Plasticity of soils and compaction energy and water content were varied to investigate the effects of these parameters on SWCCs. Several parametric models were used to describe the relation between suction and water content. Comparisons were made between the SWCC obtained for a laboratory compacted soil and the SWCC obtained for the same soil compacted in the field.

\section{Background}

Knowledge of the unsaturated behavior of compacted clay soils is needed to predict accurately the performance of these materials as liners. Increasing suctions in compacted clays due to decreases in water content modify the flow behavior of covers and bottom liners. Flow through a cover liner allows addition of water to the contained waste, resulting in increases in the amount of leachate. For a bottom liner, flow of leachate through the liner must be known to determine potential for contamination of the surrounding subsurface. In either case, one form of the governing equation for flow through a variably saturated liner, assuming onedimensional, vertical flow is

$$
C(\psi) \frac{\partial \psi}{\partial \mathrm{t}}=\frac{\partial}{\partial \mathrm{z}}\left[K(\psi)\left(\frac{\partial \psi}{\partial \mathrm{z}}+1\right)\right]
$$

where $\psi=$ pore water suction head $(\mathrm{m}) ; K(\psi)=$ unsaturated hydraulic conductivity $\left(\mathrm{m} \mathrm{s}^{-1}\right)$; and $C(\psi)=$ specific water capacity $\left(\mathrm{m}^{-1}\right) . C(\psi)$ relates pore water suction to soil water content and is equivalent to $\partial \theta / \partial \psi$, the slope of the soil water characteristic curve.

During desiccation, the saturation of a liner is reduced, and the remaining pore water is held at increasingly large suctions. The relationship between saturation and suction during the desiccation process is described using the SWCC. Knowledge of suctions and corresponding water contents in the soil can be used to predict cracking potential of liners. The onset and resulting amount of cracking can be correlated to a soil-specific critical suction level (Miller et al. 1998). Hence, the soil water characteristic curve 


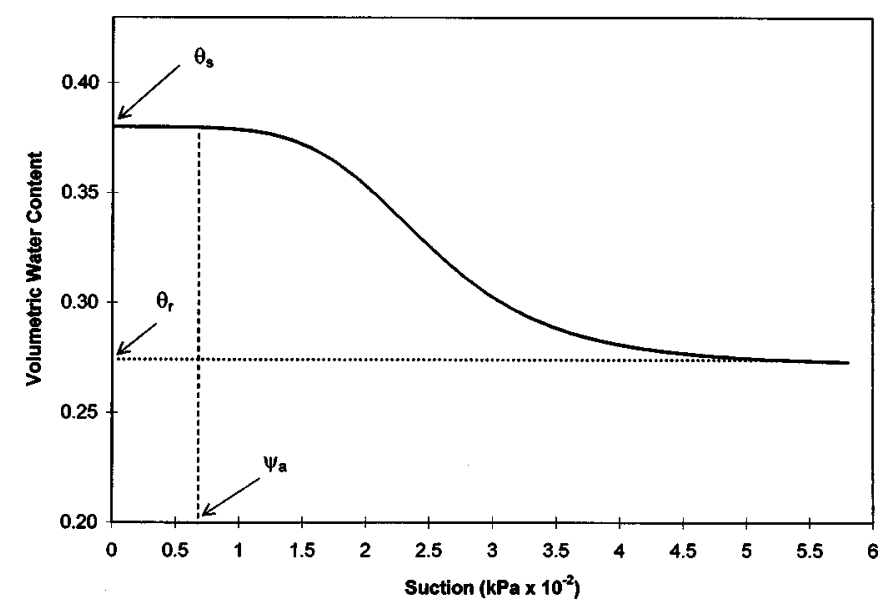

Fig. 1. Typical soil-water characteristic curve

provides critical input to the design of a compacted clay cover liner due to its potential impact on flow rates and the desiccation process.

\section{Soil Water Characteristic Curves}

A typical curve that describes the relationship between water content and pore water suction for a clay soil is presented in Fig. 1. Several defining parameters of the SWCC are shown, including air-entry suction head $\left(\psi_{a}\right)$, residual water content $\left(\theta_{r}\right)$, and saturated water content $\left(\theta_{s}\right)$. Soils with larger particle sizes, including sands and silts, would develop a SWCC that plots to the left of the curve shown in Fig. 1, with a generally smaller air-entry suction head, smaller residual water content, and smaller value of the saturated water content compared with the curve in Fig. 1. It is well known that the SWCC is hysteretic, with bounding curves defining the sorption (wetting) and desorption (drying) processes. However, standard practice is to determine only the desorption curve due to experimental difficulties associated with measurement of the sorption curve [Hillel 1980 as discussed in Tinjum et al. (1997)]. This curve is applicable only to desorption processes.

\section{Soil Water Characteristic Curve Models}

Various equations have been proposed to represent SWCC. Commonly used models include the Brooks-Corey, van Genuchten, and Fredlund and Xing equations. The Brooks-Corey (1964) model is

$$
\frac{\theta_{w}-\theta_{r}}{\theta_{s}-\theta_{r}}=\left(\frac{\psi_{a}}{\psi}\right)^{\lambda}
$$

where the optimized parameters are $\theta_{r}, \psi_{a}$, and $\lambda . \lambda$ $=$ pore-size distribution index and is related to the slope of the curve.

The van Genuchten (1980) model is

$$
\frac{\theta_{w}-\theta_{r}}{\theta_{s}-\theta_{r}}=\frac{1}{\left[1+\left(\frac{\psi}{\alpha}\right)^{n}\right]^{m}}
$$

where the optimized parameters $=\theta_{r}, \alpha, n$, and $m$. Each of these parameters is described by Leong and Rahardjo (1997). The parameter $\alpha$ is the pivot point of the curve, and its value is directly related to the value of the air-entry suction. As $\alpha$ increases, the air-entry suction also increases. The parameter $n$ controls the slope of the SWCC about the pivot point, which occurs at a normalized volumetric water content $(\Theta)$ of 0.5 , where: $\Theta=\left(\theta_{w}\right.$ $\left.-\theta_{r}\right) /\left(\theta_{s}-\theta_{r}\right)$. As $n$ increases, the sloping portion of the curve between $\psi_{a}$ and the knee (the point of inflection at the lower portion of the curve as it approaches a horizontal position) of the SWCC becomes steeper. The parameter $m$ rotates the sloping portion of the curve. As $m$ increases, the range of the curve between $\psi_{a}$ and the knee of the SWCC decreases. The stability of the curve-fitting process is improved by equating the parameter $m$ to $1-n^{-1}$ (van Genuchten et al. 1991). This relationship was adopted in this study.

The Fredlund and Xing (1994) four-parameter model is

$$
\frac{\theta_{w}}{\theta_{s}}=\frac{1}{\left\{\ln \left[e+\left(\frac{\psi}{a}\right)^{b}\right]\right\}^{c}}
$$

where the optimized parameters $=a, b$, and $c$. The parameters $a$, $b$, and $c$ of the Fredlund and Xing model are similar to the parameters $\alpha, n$, and $m$ in the van Genuchten model, respectively. Application of this model assumes that $\theta_{r}$ is small enough that it can be neglected.

The Fredlund and Xing (1994) five-parameter model is

$$
\frac{\theta_{w}-\theta_{r}}{\theta_{s}-\theta_{r}}=\frac{1}{\left\{\ln \left[e+\left(\frac{\psi}{a}\right)^{b}\right]\right\}^{c}}
$$

where the optimized parameters $=\theta_{r}, a, b$, and $c$.

A presentation of these equations and an explanation of the physical significance of the parameters is provided by Leong and Rahardjo (1997). These four models were used in this study to describe the unsaturated behavior of the test soils.

\section{Testing Program}

In this study, tests were conducted to determine SWCCs for four compacted clay soils. The testing range for these samples was $100-1,000 \mathrm{kPa}$, and the resulting conclusions should be limited to that range. The first three soils were tested to analyze effects of plasticity and compaction conditions on SWCCs. These soils were compacted in the laboratory. The fourth soil was used to analyze effects of laboratory and field compaction on the SWCC. SWCCs were developed for an undisturbed field compacted sample of the fourth soil and also for a laboratory recompacted sample of the same soil. The dry density and water content were similar for the field and laboratory compacted samples.

\section{Soils}

Soils used in the study were obtained from three landfills located in southern Michigan. Soil characterization data are presented in Table 1. Soil 1 and Soil 2 were obtained from active excavation areas used for cover and bottom liner construction for two municipal solid waste landfills in southern Michigan. One objective of the testing program was to analyze the unsaturated behavior of compacted clays that had varying plasticities. However, a soil with LL and PI values representative of a high-plasticity soil could not be obtained from local landfills. Therefore, Soil 3 was prepared by mixing Soil 2 with $25 \%$ bentonite by weight. Soil 4 was also obtained from a municipal solid waste landfill in southern Michigan.

Although mineralogical analyses were not in the scope of this research, previous investigations (Salim et al. 1996) indicate that 
Table 1. Soil Characterization

\begin{tabular}{|c|c|c|c|c|c|}
\hline & $\begin{array}{l}\text { gerty } \\
\text { gravity }\end{array}$ & $\begin{array}{c}\text { Soil } 1 \\
2.68\end{array}$ & $\begin{array}{c}\text { Soil } 2 \\
2.68\end{array}$ & $\begin{array}{c}\text { Soil } 3 \\
2.69\end{array}$ & $\begin{array}{c}\text { Soil } 4 \\
2.69\end{array}$ \\
\hline \multirow{3}{*}{ Particle size analysis } & $\%$ Sand & 56 & 3 & 2 & 0 \\
\hline & $\%$ Silt & 27 & 38 & 34 & 29 \\
\hline & $\%$ Clay & 17 & 59 & 64 & 42 \\
\hline \multirow{3}{*}{ Atterberg limits } & Unified Soil Classification System & SM & CL & $\mathrm{CH}$ & CL \\
\hline & LL & 16 & 40 & 83 & 26 \\
\hline & PI & 7 & 17 & 60 & 14 \\
\hline
\end{tabular}

the mineralogical composition of clay soils in southern Michigan are fairly similar and that site-specific mineralogical analysis may be unwarranted. A typical mineralogical composition shows the clay fraction to be dominated by three minerals with approximately $60 \%$ illite, $12 \%$ kaolinite, and $9 \%$ chlorite.

\section{Compaction}

Soils 1, 2, and 3 were compacted using reduced, standard, and modified Proctor compactive efforts. Reduced compaction is similar to standard compaction with one exception; 15 blows/ layer are used instead of 25 blows/layer (Daniel and Benson 1990). Reduced effort is used to simulate poor quality compaction procedures in the field. Compaction characteristics of the soils are presented in Table 2.

Undisturbed samples of Soil 4 were obtained from a field compacted liner using two Shelby tubes. Field compaction was conducted using a sheepsfoot roller. Water content and density of the field compacted soil were determined in the laboratory to be $13.4 \%$ and $15.1 \mathrm{kN} / \mathrm{m}^{3}$, respectively. A laboratory sample was prepared to simulate field water content and density using modified Proctor compaction procedures. The required degree of compaction was determined by calculating the ratio of the field dry density to the maximum dry density for modified compaction provided by the landfill operator. This ratio was determined to be $95 \%$. Therefore, the number of blows used in preparation of the laboratory sample was adjusted to simulate the energy applied to the field compacted soil.

\section{Determination of Soil Water Characteristic Curve}

Pressure membrane tests were conducted to determine the equilibrium water content retained in a soil subjected to pressures ranging between $100 \mathrm{kPa}$ ( 1 bar) and $1,000 \mathrm{kPa}(10 \mathrm{bar})$. Procedures described in ASTM D3152-72 (ASTM 1994) were used in the tests. The resulting data were used to construct the soil-water characteristic curves for the samples.

The testing procedure was identical for Soils 1-3. For each soil, samples were prepared using the three compactive efforts. For each compaction effort, two samples were prepared, one sample with a water content approximately $2 \%$ dry of optimum, and the other sample with a water content approximately $2 \%$ wet of optimum water content. All samples were compacted in 102- mm-diameter compaction molds. A 51-mm inside diameter steel tube with a beveled sharp cutting edge was used to extrude columns of soil from the soil sample. The extruded soil columns were then sliced using an electrical saw to prepare 10 -mm-thick and 51-mm-diameter soil specimens for use in the pressure tests. The same procedures were used for the laboratory-compacted specimens of Soil 4.

The preparation of field compacted specimens for Soil 4 was slightly different. A 150-mm-thick and 51-mm-diameter soil column was extruded from a Shelby tube. The column was then sliced and trimmed to prepare specimens with 10-mm-thickness and 51-mm-diameter.

A total of ten specimens were used to develop each SWCC (five pressure levels, two specimens at each level). Duplicate specimens were tested at each pressure level to estimate the level of experimental error. The average water content of these duplicate specimens was used in plotting the SWCC. The maximum variation between duplicate specimens was less than $8 \%$.

\section{Determination of Saturation Water Content and Residual Water Content}

The saturation water contents of Soils 1, 2, and 3 were determined using two approaches. In the first, soil samples were prepared using the procedures described in the previous section for samples used in the pressure plate tests. Additional specimens of the soils were saturated together with specimens to be used for the pressure membrane tests. Subsequent to saturation, these specimens were weighed, oven-dried for $24 \mathrm{~h}$, reweighed, and $\theta_{s}$ was calculated. The second approach for determination of saturation water content relied on phase relationships for the compacted soils, using measurements of dry density and specific gravity of the solids. All of these specimens were obtained from the same soil sample. The average of the saturation water content calculated using these two approaches was adopted for the study.

The residual water contents for Soils 1, 2, 3, and 4 were determined subsequent to an extended period of air drying. The samples were allowed to air dry in the laboratory under controlled temperature $\left(70^{\circ} \mathrm{F}\right)$ and relative humidity $(45 \%)$ for a period of three weeks. The samples were weighed and oven dried for $24 \mathrm{~h}$ to determine volumetric residual water content $\left(\theta_{r}\right)$.

Table 2. Compaction Characteristics of Soils

\begin{tabular}{|c|c|c|c|c|c|c|c|c|c|}
\hline \multirow{2}{*}{$\frac{\text { Characteristic }}{\text { Compaction effort }}$} & \multicolumn{3}{|c|}{ Soil 1} & \multicolumn{3}{|c|}{ Soil 2} & \multicolumn{3}{|c|}{ Soil 3} \\
\hline & Reduced & Standard & Modified & Reduced & Standard & Modified & Reduced & Standard & Modified \\
\hline Maximum unit weight $\left(\mathrm{kN} / \mathrm{m}^{3}\right)$ & 19.7 & 20.0 & 21.7 & 15.2 & 15.8 & 17.6 & 13.4 & 14.7 & 16.7 \\
\hline Optimum water content (\%) & 10.8 & 9.0 & 6.4 & 25.6 & 24.2 & 19.2 & 34.2 & 29.1 & 22.5 \\
\hline
\end{tabular}




\section{Results and Discussion}

SWCCs were developed using data from pressure membrane tests. The four parametric models [Eqs. (2)-(5)] were used to develop SWCCs. Comparisons were made between the fits provided by the various models and the measured data. Effects of soil type and compaction conditions on SWCCs were also analyzed.

\section{Comparison between Soil Water Characteristic Curve Models}

Data obtained in the tests were fit to the models described by Eqs. (2)-(5). An optimization routine was used to fit the parametric models to the measured data by altering the fitted parameters iteratively until the squared differences between the predicted and measured $\theta(\psi)$ data were minimized. The sum of the squared residuals (SSR) is defined as

$$
\mathrm{SSR}=\sum_{i=1}^{n} w_{i}\left(\theta_{w i}-\theta_{c i}\right)^{2}
$$

where $w_{i}=$ weighting factor; $\theta_{w i}=$ measured water content at a certain pressure level; and $\theta_{c i}=$ calculated water content from each model at the same pressure level. The weighting factor was set equal to 1.0 as all data points were assumed to be equally significant. The best fit of each model to the measured data was assumed to be the one that resulted in the minimum SSR value. The SSR values and model parameters obtained for each condition are presented in Tables 3-6. In all cases, the SSR is less than $10^{-3}$, which is within the range of SSR values obtained by Leong and Rahardjo (1997) in similar studies. Each of the four models provide an acceptable fit to the experimental data.

The optimization process resulted in a set of parameters which provided the best fit of the measured data points to each model. The fitted parameters for each soil and compaction condition are presented in Tables 3-6. The best-fit value of the residual water content $\left(\theta_{r}\right)$ varied significantly between models, compaction conditions, and soils (Tables 3-6). The Brooks and Corey values of $\theta_{r}$ are the smallest, except for modified compaction conditions for Soil 3. The best-fit values for $\theta_{r}$ ranged between 0.0 and 0.38 . These residual water contents are within the range of values provided in the literature (Leong and Rahardjo 1997; Tinjum et al. 1997).

Three of the parametric models [Brooks and Corey, (BC), van Genuchten (VG), and Fredlund and Xing five parameter (FX5)] include $\theta_{r}$ as one of the fitted parameters (Tables 3-6). During the optimization technique, the value of $\theta_{r}$ was constrained to be greater than or equal to 0.0 . The experimentally determined values of $\theta_{r}$ are presented in Table 7. For each soil, the measured value of $\theta_{r}$ increases with increasing compaction effort. The bestfit values of $\theta_{r}$ do not exhibit the same trends observed in the measured values of $\theta_{r}$. All models predict zero values for $\theta_{r}$ for Soil 1. For Soil 2, BC predicts a zero value for $\theta_{r}$ for all conditions, while the other two models have some nonzero values, with a maximum value of 0.33 for modified compaction, dry of optimum. The VG model predicts higher values of $\theta_{r}$ for Soil 3 (maximum of 0.38). The measured values (Table 7) suggest that Soil 3 has the greatest moisture retention of the four soils, but it is much less than predicted by the VG model. Overall, there is poor correlation between the measured and predicted values of $\theta_{r}$. Also, there is little similarity between the $\theta_{r}$ values predicted by the three models. One explanation for this is the lack of measured SWCC data in the high-suction range. The inability of the models to converge to a common value of water content at large suctions indicates that these models should not be used to extrapolate behavior at the extreme end of the curve.

Although each model yields a different set of best-fit parameters, the resulting curves are very similar, especially in the measured range of suctions $(100-1,000 \mathrm{kPa})$. The similarity between the BC, VG, and two FX models are presented in Fig. 2 for Soil

Table 3. Soil Water Characteristic Curve Fit Parameters for Soil 1

\begin{tabular}{|c|c|c|c|c|c|c|c|}
\hline Model & Parameter & Modified/dry & Modified/wet & Standard/dry & Standard/wet & Reduced/dry & Reduced/wet \\
\hline & $\Psi_{a}\left(\mathrm{kPa} \times 10^{-2}\right)$ & 0.19 & 0.01 & 0.08 & 0.01 & 0.04 & 0.01 \\
\hline & $\lambda_{r}$ & 0.13 & 0.08 & 0.14 & 0.08 & 0.14 & 0.07 \\
\hline \multirow[t]{4}{*}{$\mathrm{BC}$} & $\theta_{r}$ & 0.00 & 0.00 & 0.00 & 0.00 & 0.00 & 0.00 \\
\hline & SSR & $1.4 \mathrm{E}-04$ & $4.8 \mathrm{E}-05$ & $4.6 \mathrm{E}-05$ & $9.4 \mathrm{E}-05$ & $6.9 \mathrm{E}-05$ & $1.4 \mathrm{E}-06$ \\
\hline & $\alpha\left(\mathrm{kPa} \times 10^{-2}\right)$ & 0.26 & 0.01 & 0.09 & 0.01 & 0.04 & 0.01 \\
\hline & $n$ & 1.15 & 1.08 & 1.15 & 1.08 & 1.14 & 1.07 \\
\hline \multirow[t]{5}{*}{ VG } & $m_{r}$ & 0.13 & 0.08 & 0.13 & 0.07 & 0.12 & 0.07 \\
\hline & $\theta_{r}$ & 0.00 & 0.00 & 0.00 & 0.00 & 0.00 & 0.00 \\
\hline & SSR & $1.1 \mathrm{E}-04$ & $4.8 \mathrm{E}-05$ & $4.2 \mathrm{E}-05$ & $9.4 \mathrm{E}-05$ & $6.6 \mathrm{E}-05$ & $1.4 \mathrm{E}-06$ \\
\hline & $a\left(\mathrm{kPa} \times 10^{-2}\right)$ & 30.88 & 9.11 & 34.62 & 18.67 & 33.48 & 0.30 \\
\hline & $b$ & 0.43 & 0.22 & 0.33 & 0.19 & 0.28 & 0.17 \\
\hline \multirow[t]{4}{*}{ FX4 } & $c$ & 2.97 & 2.20 & 3.56 & 2.52 & 3.68 & 1.68 \\
\hline & SSR & $7.0 \mathrm{E}-05$ & $3.3 \mathrm{E}-05$ & $1.7 \mathrm{E}-05$ & $7.6 \mathrm{E}-05$ & $2.8 \mathrm{E}-05$ & $6.4 \mathrm{E}-07$ \\
\hline & $a\left(\mathrm{kPa} \times 10^{-2}\right)$ & 30.88 & 9.11 & 34.62 & 18.67 & 33.48 & 0.30 \\
\hline & $b$ & 0.43 & 0.22 & 0.33 & 0.19 & 0.28 & 0.17 \\
\hline \multirow[t]{3}{*}{ FX5 } & $c_{r}$ & 2.97 & 2.20 & 3.56 & 2.52 & 3.68 & 1.68 \\
\hline & $\theta_{r}$ & 0.00 & 0.00 & 0.00 & 0.00 & 0.00 & 0.00 \\
\hline & SSR & $7.0 \mathrm{E}-05$ & $3.3 \mathrm{E}-05$ & $1.7 \mathrm{E}-05$ & $7.6 \mathrm{E}-05$ & $2.8 \mathrm{E}-05$ & $6.4 \mathrm{E}-07$ \\
\hline
\end{tabular}


Table 4. Soil Water Characteristic Curve Fit Parameters for Soil 2

\begin{tabular}{|c|c|c|c|c|c|c|c|}
\hline Model & Parameter & Modified/dry & Modified/wet & Standard/dry & Standard/wet & Reduced/dry & Reduced/wet \\
\hline & $\Psi_{a}\left(\mathrm{kPa} \times 10^{-2}\right)$ & 0.48 & 0.18 & 0.15 & 0.37 & 0.47 & 0.36 \\
\hline & $\lambda_{r}$ & 0.11 & 0.09 & 0.07 & 0.11 & 0.1 & 0.12 \\
\hline \multirow[t]{4}{*}{$\mathrm{BC}$} & $\theta_{r}$ & 0.00 & 0.00 & 0.00 & 0.00 & 0.00 & 0.00 \\
\hline & SSR & $2.1 \mathrm{E}-04$ & $1.6 \mathrm{E}-04$ & $1.9 \mathrm{E}-04$ & $3.7 \mathrm{E}-04$ & $1.8 \mathrm{E}-04$ & $1.4 \mathrm{E}-04$ \\
\hline & $\alpha\left(\mathrm{kPa} \times 10^{-2}\right)$ & 1.12 & 0.24 & 0.20 & 0.72 & 1.02 & 0.61 \\
\hline & $n$ & 1.45 & 1.10 & 1.07 & 1.14 & 1.15 & 1.14 \\
\hline \multirow[t]{5}{*}{ VG } & $m_{r}$ & 0.31 & 0.09 & 0.07 & 0.12 & 0.13 & 0.12 \\
\hline & $\theta_{r}$ & 0.25 & 0.00 & 0.00 & 0.00 & 0.03 & 0.00 \\
\hline & SSR & $1.5 \mathrm{E}-04$ & $1.3 \mathrm{E}-04$ & $1.7 \mathrm{E}-04$ & $2.4 \mathrm{E}-04$ & $1.0 \mathrm{E}-04$ & $8.8 \mathrm{E}-05$ \\
\hline & $a\left(\mathrm{kPa} \times 10^{-2}\right)$ & 0.95 & 18.56 & 17.24 & 20.67 & 1.39 & 1.31 \\
\hline & $b$ & 1.30 & 0.42 & 0.40 & 0.57 & 0.99 & 0.80 \\
\hline \multirow[t]{4}{*}{ FX4 } & $c$ & 0.30 & 1.72 & 1.27 & 1.89 & 0.39 & 0.56 \\
\hline & SSR & $1.5 \mathrm{E}-04$ & $7.0 \mathrm{E}-05$ & $1.3 \mathrm{E}-04$ & $1.6 \mathrm{E}-04$ & $9.4 \mathrm{E}-05$ & $8.0 \mathrm{E}-05$ \\
\hline & $a\left(\mathrm{kPa} \times 10^{-2}\right)$ & 1594.62 & 18.56 & 17.24 & 20.67 & 1428.84 & 595.18 \\
\hline & $b$ & 1.00 & 0.42 & 0.40 & 0.57 & 0.89 & 0.69 \\
\hline \multirow[t]{3}{*}{ FX5 } & $c_{r}$ & 1324.24 & 1.72 & 1.27 & 1.89 & 507.28 & 78.75 \\
\hline & $\theta_{r}$ & 0.33 & 0.00 & 0.00 & 0.00 & 0.31 & 0.28 \\
\hline & SSR & $8.8 \mathrm{E}-05$ & $7.0 \mathrm{E}-05$ & $1.3 \mathrm{E}-04$ & $1.6 \mathrm{E}-04$ & $7.4 \mathrm{E}-05$ & $7.7 \mathrm{E}-05$ \\
\hline
\end{tabular}

3 compacted with modified effort at wet of optimum water content. Table 8 compares the calculated water contents using each model for four values of suction. The maximum difference between calculated water contents decreases as the pore water suction increases. The variation between model representations of the SWCC is greatest in the suction range of $0-100 \mathrm{kPa}$. There is no experimental data in this range and a different interpolation is obtained from each model for the curve between $0-100 \mathrm{kPa}$.
Tables 3-6 also provide information on the best-fit values of $\psi_{a}$ from the BC curve fit. $\psi_{a}$ generally decreases with decreasing compaction effort, with some exceptions for the Soil 2 curve fit. $\psi_{a}$ is smaller for wet of optimum compaction for all conditions except Soil 2, standard compaction. In all cases, $\psi_{a}$ increases with increasing soil plasticity. Therefore, although $\psi_{a}$ was not directly measured, the BC model provided expected predictions for $\psi_{a}$.

Parameter $\alpha$, of the VG model, follows the same trends as the

Table 5. Soil Water Characteristic Curve Fit Parameters for Soil 3

\begin{tabular}{|c|c|c|c|c|c|c|c|}
\hline Model & Parameter & Modifiedd/ry & Modified/wet & Standard/dry & Standard/wet & Reduced/dry & Reduced/wet \\
\hline & $\Psi_{a}\left(\mathrm{kPa} \times 10^{-2}\right)$ & 1.58 & 1.31 & 1.21 & 0.7 & 0.63 & 0.56 \\
\hline & $\lambda_{r}$ & 0.34 & 0.2 & 0.7 & 0.17 & 0.18 & 0.17 \\
\hline \multirow[t]{4}{*}{$\mathrm{BC}$} & $\theta_{r}$ & 0.24 & 0.10 & 0.00 & 0.00 & 0.00 & 0.00 \\
\hline & SSR & $1.3 \mathrm{E}-05$ & $8.6 \mathrm{E}-06$ & $2.8 \mathrm{E}-06$ & $5.1 \mathrm{E}-05$ & $1.0 \mathrm{E}-04$ & $8.8 \mathrm{E}-05$ \\
\hline & $\alpha\left(\mathrm{kPa} \times 10^{-2}\right)$ & 3.05 & 2.73 & 2.60 & 1.67 & 1.44 & 1.21 \\
\hline & $n$ & 2.72 & 2.07 & 1.90 & 1.65 & 1.74 & 1.45 \\
\hline \multirow[t]{5}{*}{ VG } & $m_{r}$ & 0.63 & 0.52 & 0.47 & 0.39 & 0.43 & 0.31 \\
\hline & $\theta_{r}$ & 0.38 & 0.35 & 0.31 & 0.28 & 0.27 & 0.21 \\
\hline & SSR & $3.6 \mathrm{E}-06$ & $3.7 \mathrm{E}-05$ & $2.8 \mathrm{E}-06$ & $5.2 \mathrm{E}-05$ & $4.8 \mathrm{E}-05$ & $2.1 \mathrm{E}-05$ \\
\hline & $a\left(\mathrm{kPa} \times 10^{-2}\right)$ & 2.03 & 1.84 & 1.84 & 1.27 & 1.09 & 1.11 \\
\hline & $b$ & 3.40 & 2.38 & 2.00 & 1.70 & 1.76 & 1.35 \\
\hline \multirow[t]{4}{*}{ FX4 } & $c$ & 0.18 & 0.23 & 0.29 & 0.35 & 0.37 & 0.44 \\
\hline & SSR & $1.3 \mathrm{E}-09$ & $3.0 \mathrm{E}-05$ & $2.0 \mathrm{E}-06$ & $4.9 \mathrm{E}-05$ & $5.2 \mathrm{E}-05$ & $2.2 \mathrm{E}-05$ \\
\hline & $a\left(\mathrm{kPa} \times 10^{-2}\right)$ & 2.03 & 1.84 & 1.84 & 1.27 & 2.78 & 1.11 \\
\hline & $b$ & 3.40 & 2.38 & 2.00 & 1.70 & 1.39 & 1.35 \\
\hline \multirow[t]{3}{*}{ FX5 } & $c_{r}$ & 0.18 & 0.23 & 0.29 & 0.35 & 2.64 & 0.44 \\
\hline & $\theta_{r}$ & 0.00 & 0.00 & 0.00 & 0.00 & 0.31 & 0.00 \\
\hline & SSR & $1.3 \mathrm{E}-09$ & $3.0 \mathrm{E}-05$ & $2.0 \mathrm{E}-06$ & $4.9 \mathrm{E}-05$ & $4.3 \mathrm{E}-05$ & $2.2 \mathrm{E}-05$ \\
\hline
\end{tabular}


Table 6. Soil Water Characteristic Curve Fit Parameters for Soil 4

\begin{tabular}{lccc}
\hline Model & Parameter & Field & Laboratory \\
\hline \multirow{4}{*}{ BC } & $\Psi_{a}\left(\mathrm{kPa} \times 10^{-2}\right)$ & 0.71 & 0.53 \\
& $b_{r}$ & 0.09 & 0.11 \\
& $\theta_{r}$ & 0.00 & 0.00 \\
& $\mathrm{SSR}$ & $1.4 \mathrm{E}-04$ & $8.0 \mathrm{E}-05$ \\
& $\alpha\left(\mathrm{kPa} \times 10^{-2}\right)$ & 2.16 & 1.18 \\
$\mathrm{VG}$ & $n$ & 1.16 & 1.16 \\
& $m_{r}$ & 0.14 & 0.14 \\
& $\theta_{r}$ & 0.00 & 0.00 \\
$\mathrm{FX} 4$ & $\mathrm{SSR}$ & $9.9 \mathrm{E}-05$ & $3.2 \mathrm{E}-05$ \\
& $a\left(\mathrm{kPa} \times 10^{-2}\right)$ & 28.83 & 26.80 \\
& $b$ & 0.75 & 0.64 \\
& $c$ & 1.87 & 2.16 \\
& $\mathrm{SSR}$ & $8.3 \mathrm{E}-05$ & $1.1 \mathrm{E}-05$ \\
& $a\left(\mathrm{kPa} \times 10^{-2}\right)$ & 28.83 & 26.80 \\
& $b$ & 0.75 & 0.64 \\
& $c_{r}$ & 1.87 & 2.16 \\
& $\theta_{r}$ & 0.00 & 0.00 \\
& $\mathrm{SSR}$ & $8.3 \mathrm{E}-05$ & $1.1 \mathrm{E}-05$ \\
\hline
\end{tabular}

$\psi_{a}$ parameter of the BC model. These parameters are related linearly on a logarithmic scale, as shown in Fig. 3. The value of $\alpha$ in the VG model varied over several orders of magnitude, between 1.0 and $305 \mathrm{kPa}$. Leong and Rahardjo (1997) presented a range of $2.82-281 \mathrm{kPa}$ for the clay SWCC curve fits for the clay soils that they investigated.

The value of the FX " $a$ " parameter shows significant variation between soils and between compaction conditions. The value varied between 30 and 159,462 kPa, although most values fall within a narrower band. Fredlund and Xing (1994) reported a similar wide variation in the values they observed for parameter " $a$." Their values covered a range of $10-15,150 \mathrm{kPa}$.

\section{Variation of Soil Water Characteristic Curve with Soil Type}

The SWCCs corresponding to the van Genuchten curve fit are shown in Fig. 4 for each compaction condition for Soils 1-3. In all cases, the SWCCs plot in order of decreasing plasticity index. For example, for the dry of optimum compaction with modified effort, Soil $3(P I=60)$ plots above Soil $2(P I=17)$ which plots above Soil $1(\mathrm{PI}=7)$. This trend is consistent for all six compaction conditions (Fig. 4). This order of soils is also indicative of the clay fraction present in each soil sample (Table 1). Increased clay content generally leads to an increase in the amount of water retained at a certain suction. In Fig. 4(a) (modified, dry of optimum), Soils 3, 2, and 1 retain approximately 44, 36, and $18.5 \%$ water, respectively, at a suction of $500 \mathrm{kPa}$. It was also observed that for each compaction condition, the decrease in volumetric water content as suction increases from 100 to $1,000 \mathrm{kPa}$ increases as the PI increases. Table 9 shows the percentage reduction in water content for each compaction condition as the suction is increased from 100 to $1,000 \mathrm{kPa}$. Except for standard compaction, dry of optimum water content, the amount of water removed in the investigated soils increases with increasing soil PI. As plasticity increases, porosity (and therefore $\theta_{s}$ ) increases. Therefore, more water is available for removal. Soil 1, the low-plasticity soil, exhibits a flat SWCC, leading to the smallest release of water for the given change in suction. The more significant fraction of moisture was removed in the $0-100 \mathrm{kPa}$ pressure range.

\section{Variation of Soil Water Characteristic Curve with Compaction Conditions}

Effect of compaction effort on SWCC for each soil can be evaluated from the information provided in Fig. 4, reconfigured as shown in Fig. 5 for Soil 3. SWCCs for higher-compaction efforts generally plot above the SWCCs for lower-compaction efforts. Soils compacted with high-compaction efforts have small pores. For the same water content, pore water suctions increase with decreasing pore sizes, leading to the higher-compaction efforts plotting above lower-compaction efforts. These trends were also observed for Soils 1 and 2. Similar behavior was observed by Tinjum et al. (1997). The impact of compaction effort is more significant for the high-plasticity soil (Soil 3) than the lowplasticity soils. This can be explained by the fact that increasing compaction efforts lead to the largest percentage change in density (and also porosity) for the high-plasticity soil (Table 2). Therefore, the density (and also porosity) spans a larger range for Soil 3 which leads to a more pronounced variation in the respective locations of the SWCC curves for Soil 3.

SWCCs for different compaction efforts cross over one another in Fig. 5. At the crossover point, the relative positions of the curves are reversed. This crossover occurs because the soil with the largest porosity, i.e., the soil compacted with the lowest effort, will have the largest value of $\theta_{s}$. However, as suctions increase beyond the crossover point, the water content associated with any suction for the least compacted soil is less than that for the more compacted soils. This crossover occurs at approximately $100 \mathrm{kPa}$ of suction, which is also the approximate value of the air-entry suction.

Variation in the compaction water content resulted in insignificant and unsystematic changes in the resulting SWCC, as shown in Fig. 6 for Soil 3. For both modified and standard efforts, the SWCCs are essentially concidient, while for reduced effort the wet of optimum curve plots slightly above the dry of optimum curve. For the nine cases investigated for Soils 1-3, five show insignificant variation for compaction wet and dry of optimum, three show dry above wet, and one shows wet above dry. The data of Marinho and Chandler (1993) indicate the SWCC was essentially independent of the compaction water content, similar to the results of the present investigation. When Tinjum et al. (1997) normalized their water content data, the samples compacted wet of optimum plotted above samples compacted dry of optimum. The normalized form was also considered for the data of the

Table 7. Measured Residual Water Content $\left(\theta_{r}\right)$

\begin{tabular}{lcccccc}
\hline Soil & Reduced/dry & Reduced/wet & Standard/dry & Standard/wet & Modified/dry & Modified/wet \\
\hline 1 & 0.016 & 0.015 & 0.016 & 0.016 & 0.018 & 0.018 \\
2 & 0.029 & 0.028 & 0.031 & 0.029 & 0.033 \\
3 & 0.052 & 0.052 & 0.057 & 0.057 & 0.062 \\
4 & & & & & 0.062 & 0.030 \\
\hline
\end{tabular}




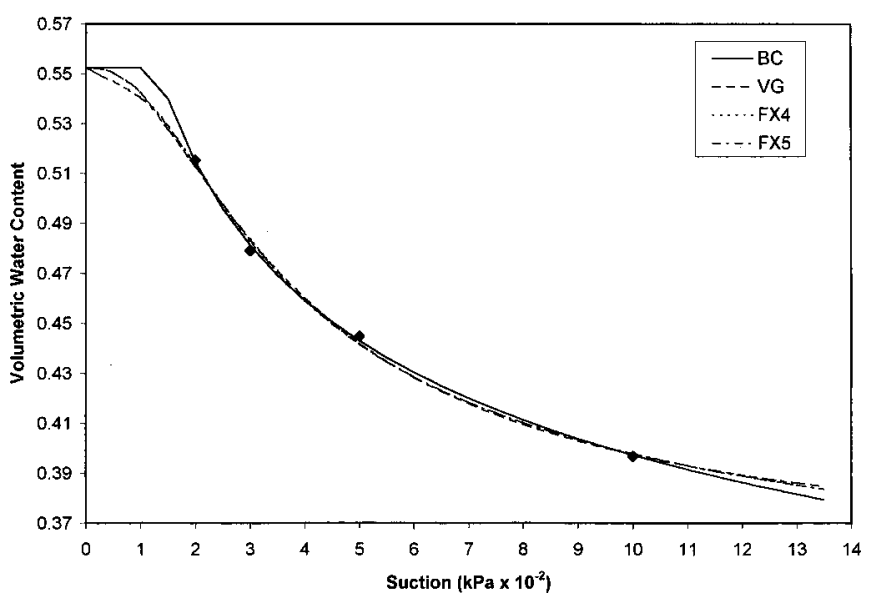

Fig. 2. Soil water characteristic curve models for Soil 3, modified compaction effort, wet of optimum

present investigation, but the conclusions were similar to those for the volumetric form. One explanation for the insignificant impact of compaction water content is the limited range of water contents considered in the present investigations. A range of $4 \%$ water content overall was attempted $(2 \%$ wet and $2 \%$ dry of optimum); however, the typical range was approximately $3.5 \%$.

The four models represent the SWCC behavior of both the field compacted and laboratory compacted specimens of Soil 4 with high correlation. SSR values range between $10^{-4}$ and $10^{-5}$ (Table 6). Fig. 7 shows the van Genuchten curve fit for both compaction conditions. There is little variation between the field compacted and laboratory compacted values of the best-fit parameters. The best-fit value of $\theta_{r}$ is identical for the two compaction conditions (at a value of 0.0 ), while the variation between all other fitted parameters is less than the variation observed due to differences in the laboratory compaction effort utilized for Soils $1-3$. These results suggest that as long as the compaction conditions (effort and water content) are similar, the compaction method has only limited influence on the behavior of the SWCC. This finding may be significant since it suggests that laboratory determined SWCCs should adequately represent the field behavior of the soils. However, more testing is required to verify the similarity between SWCCs of laboratory compacted and field compacted soils.

\section{Practical Applications of Results}

The susceptibility of a clay liner to desiccation cracking can be inferred from the SWCC for a cover liner soil. Additional studies, similar to those in Miller et al. (1998) could be completed to

Table 8. Volumetric Water Content Calculated using Four Models for Soil 3 (Modified Compaction Effort, Wet of Optimum Water Content)

\begin{tabular}{lccccc}
\hline Suction $(\mathrm{kPa})$ & BC & VG & FX4 & FX5 & $\begin{array}{c}\text { Maximum } \\
\text { difference } \\
(\%)\end{array}$ \\
\hline 50 & 0.652 & 0.549 & 0.550 & 0.550 & 15.7 \\
100 & 0.578 & 0.540 & 0.542 & 0.542 & 6.5 \\
500 & 0.443 & 0.442 & 0.442 & 0.442 & 0.3 \\
1,000 & 0.397 & 0.398 & 0.398 & 0.398 & 0.2 \\
\hline
\end{tabular}

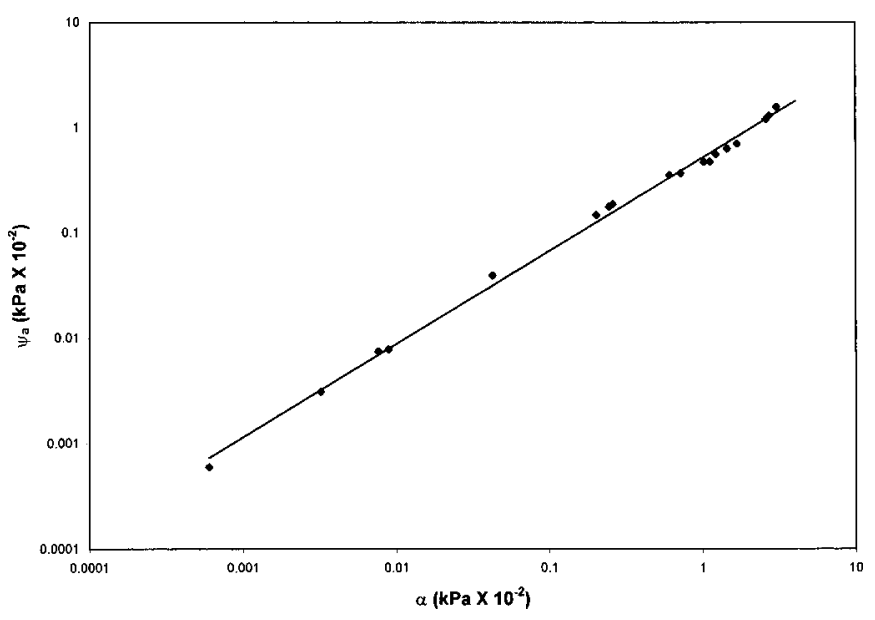

Fig. 3. Relation between the air-entry pressure head of Brooks and Corey model and $\alpha$ of van Genuchten model

determine the critical suction associated with the onset of cracking for each of the four soils. The water content corresponding to the critical suction could be determined from the SWCC. For example, if the critical suction associated with each soil is 1,000 $\mathrm{kPa}$, the volumetric water content associated with crack initiation for modified compaction effort, wet of optimum conditions is $0.14,0.32$, and 0.40 for Soils 1,2 , and 3, respectively. A numerical model of the cover liner could be implemented to predict the minimum water content for various climate scenarios, thereby determining crack susceptibility.

It was observed that when the SWCC data of this investigation is represented using a semilogarithmic plot, a linear relationship is obtained. The semilogarithmic representation of the experimental data for modified compaction effort, dry of optimum water content is presented in Fig. 8 for Soils 1-3. Similar behavior was also observed for standard and reduced compaction conditions. The best-fit straight line shown in this figure represents the behavior of the five measured data points. This is similar to the findings of Marinho and Chandler (1993) and Ho et al. (1992). Fig. 8 also shows the linear relationship developed using only two measured data points, corresponding to suctions of 100 and 1,000 $\mathrm{kPa}$. The straight line defined by these two data points is nearly identical to the best-fit line for all five data points. This suggests that under certain conditions it may be adequate to define the SWCC behavior using a two-point analysis. For the soils of this investigation, the behavior between suctions of 100 and $1,000 \mathrm{kPa}$ can be predicted using experimentally determined water contents at the endpoints of this suction range.

\section{Conclusions}

Soil water characteristic curves were developed for four compacted clay soils using a pressure membrane apparatus. The SWCCs for the soils were represented well using any of the four common SWCC models: Brooks and Corey, van Genuchten, Fredlund and Xing four-parameter, and Fredlund and Xing fiveparameter. SSR values were less than $10^{-3}$ in all cases.

The individual curve-fit parameters varied significantly, in some cases over several orders of magnitude, for the different soils and compaction conditions investigated. The best-fit values of residual water content $\left(\theta_{r}\right)$ did not correspond well to the measured values. This may be attributed to the lack of experimen- 


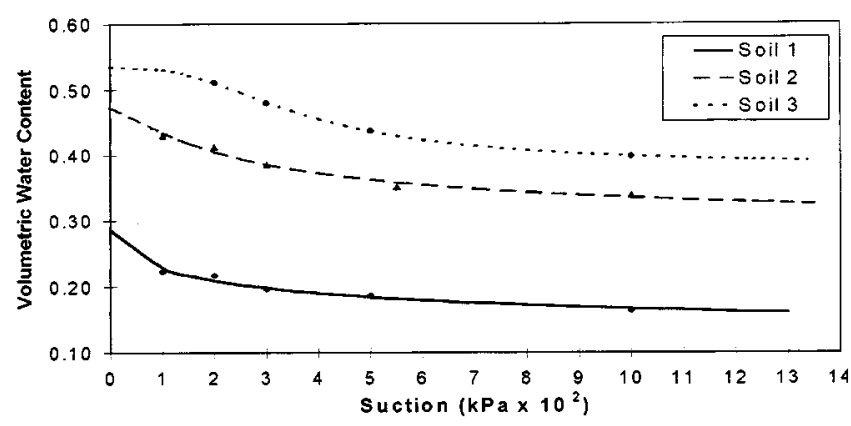

Dry of Optimum

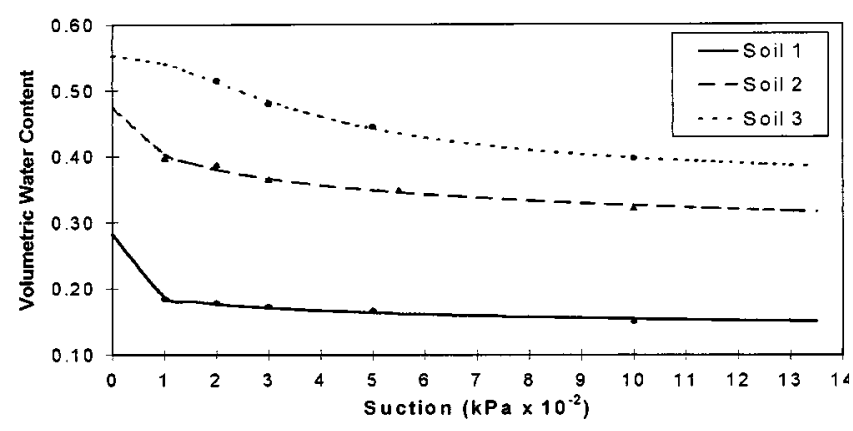

Wet of Optimum

(a)

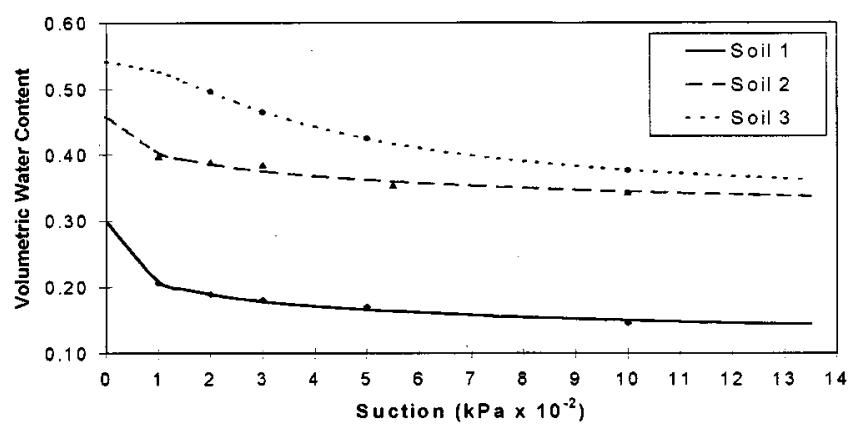

Dry of Optimum

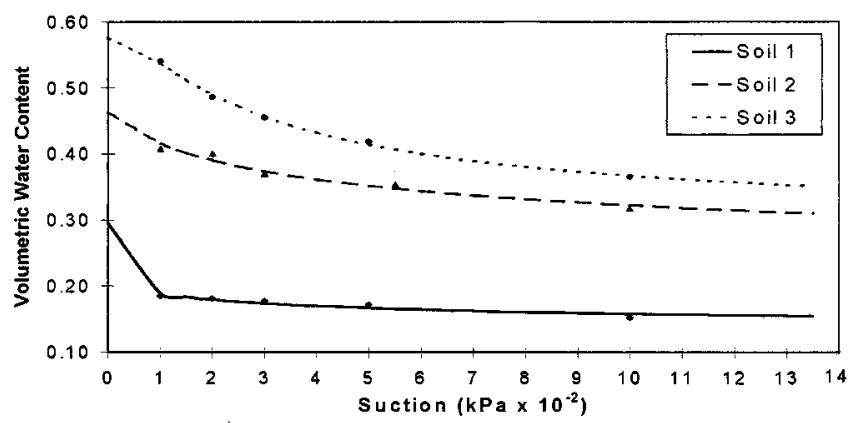

Wet of Optimum

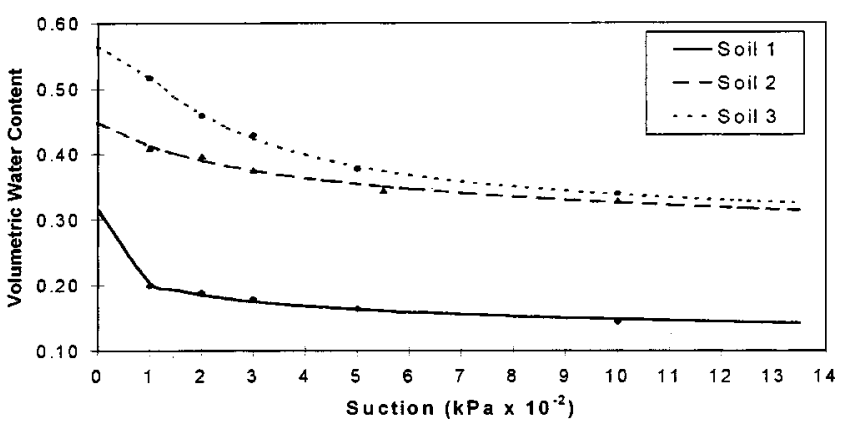

Dry of Optimum

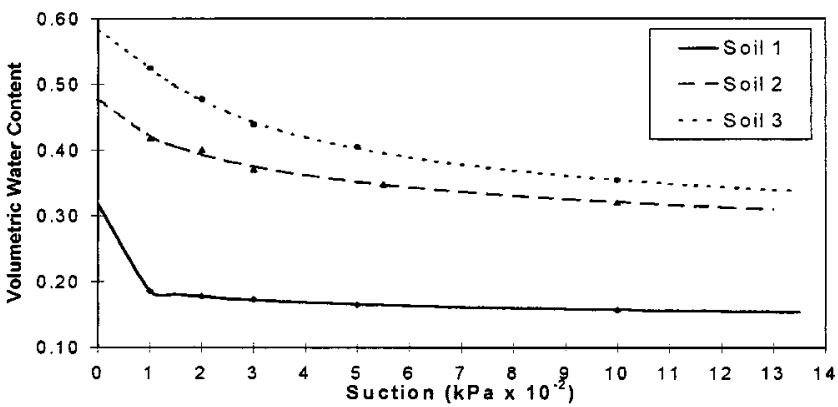

(c)

Wet of Optimum

(b)

Fig. 4. Variation in soil water characteristic curve behavior due to soil type (a) modified effort, (b) standard effort, (c) reduced effort

Table 9. Change in Volumetric Water Content due to Change in Suction from 100 to $1,000 \mathrm{kPa}(\%)$

\begin{tabular}{lcccccc}
\hline Soil & Reduced/dry & Reduced/wet & Standard/dry & Standard/wet & Modified/dry & Modified/wet \\
\hline 1 & 5.48 & 2.84 & 6.07 & 3.25 & 5.93 & 3.41 \\
2 & 8.03 & 9.73 & 5.38 & 8.97 & 9.17 & 7.61 \\
3 & 17.71 & 17.03 & 17.73 & 17.47 & 17.19 & 17.72 \\
\hline
\end{tabular}




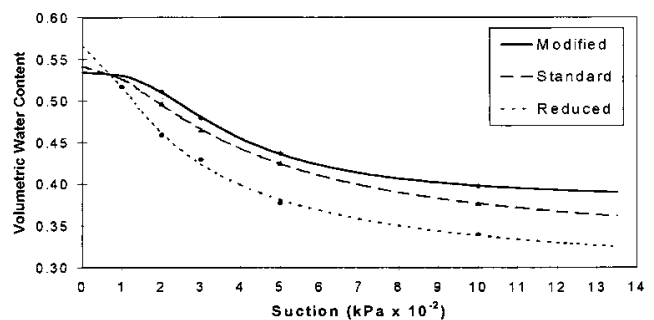

Dry of Optimum

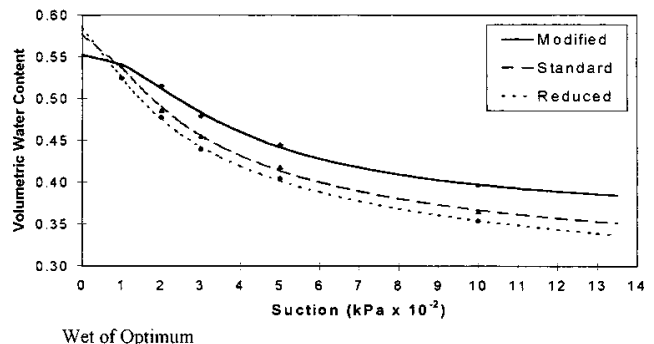

Fig. 5. Variation in soil water characteristic curve behavior due to compaction effort for Soil 3

tal data for suctions greater than $1,000 \mathrm{kPa}$ and to the lack of a standardized method for experimental determination of $\theta_{r}$. The curve-fit values of the air-entry suction head generally followed expected trends based on soil plasticity and compaction effort. A linear logarithmic relationship between the BC air-entry suction head $\left(\psi_{a}\right)$ and the VG $\alpha$ parameter was developed.
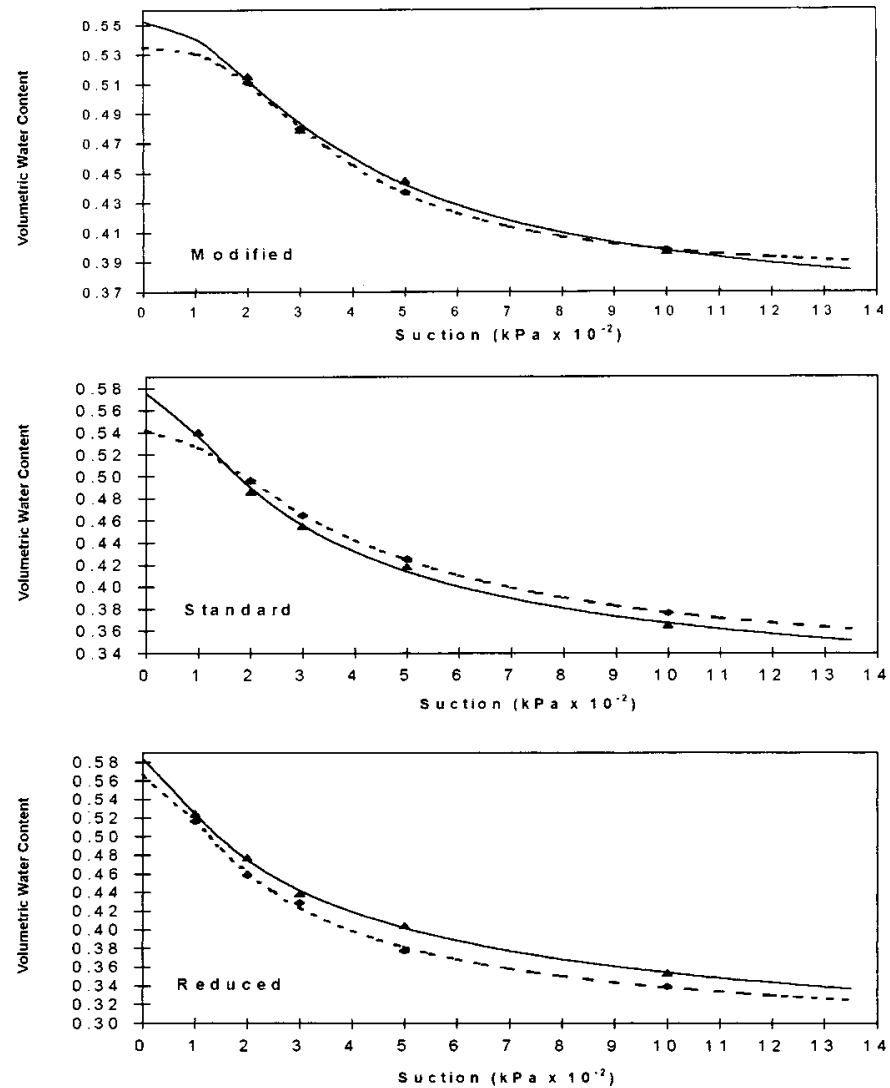

Fig. 6. Variation in soil water characteristic curve behavior due to compaction water content

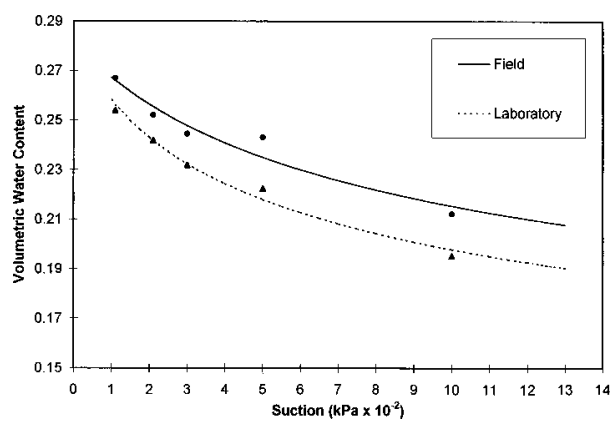

Fig. 7. Variation in soil water characteristic curve behavior between field compacted and laboratory compacted samples

Variations in SWCCs due to soil type and compaction conditions were analyzed. The relative location of SWCC plots followed the order of soil plasticity and clay content, with the highest-plasticity soils plotting above the lower-plasticity soils. In addition, soils plotted in order of increasing compaction effort, with modified effort plotting above standard and reduced efforts. For the limited range of water contents examined in this investigation, there was no significant or systematic relationship between compaction water content and SWCC behavior. In addition, there was no significant difference between the SWCC behavior of the field compacted and laboratory compacted specimens.

Linear SWCCs were obtained when semilogarithmic plots were used to represent water content and suction data. The straight-line behavior between suctions of 100 and $1,000 \mathrm{kPa}$ could be adequately described using measured data at only the two endpoints.

The SWCC is a necessary input to solution of a variety of geoenvironmental problems. Examples include the prediction of flow rates and volumes through a compacted clay liner. In addition, SWCCs can be used for evaluating desiccation behavior of liner soils. The four common models of SWCC behavior evaluated in this study were shown to provide an acceptable level of fit to the experimentally determined SWCCs of compacted clay soils of varying plasticity and compaction conditions. Further study is required to test the reliability of the individual curve-fit parameters obtained from the models and to verify the applicability of existing models over a broader range of suction conditions than evaluated in this study.

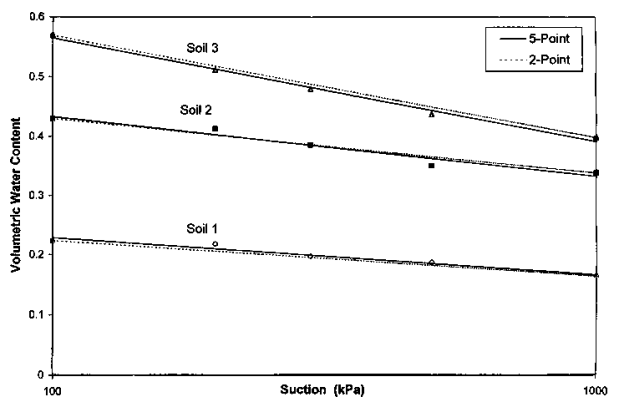

Fig. 8. Soil water characteristic curve data presented in linear, semilogarithmic form 


\section{Acknowledgment}

Funding for this study was provided by the National Science Foundation under Grant No. CMS-9713922.

\section{References}

ASTM. (1994). "Standard test method for capillary-moisture relationships for fine-textured soils by pressure-membrane apparatus." Designation: D 3152-72, West Conshohocken, Pa.

Brooks, R. H., and Corey, A. T. (1964). "Hydraulic properties of porous medium." Hydrology Paper No. 3, Civil Engineering Dept., Colorado State Univ., Fort Collins, Colo.

Daniel, D. E., and Benson, C. H. (1990). "Water content-density criteria for compacted soil liners." J. Geotech. Eng., 116(12), 1811-1830.

Fredlund, D. G., and Xing, A. (1994). "Equations for the soil-water characteristic curve." Can. Geotech. J., 31, 521-532.

Hillel, D. (1980). Fundamentals of soil physics, Academic, San Diego.

Ho, D. Y. F., Fredlund, D. G., and Rahardjo, H. (1992). "Volume change indices during loading and unloading of an unsaturated soil." Can. Geotech. J., 29, 195-207.
Leong, E. C., and Rahardjo, H. (1997). "A review on soil-water characteristic curve equations." J. Geotech. Geoenviron. Eng., 123(12), 1106-1117.

Marinho, F. A., and Chandler, R. J. (1993). "Aspects of the behavior of clays on drying." Unsaturated soils-Geotechnical special publication No. 39, S. Houston and W. Wray, eds., ASCE, New York.

Miller, C. J., Mi, H., and Yesiller, N. (1998). "Experimental analysis of desiccation crack propagation in clay liners." J. Am. Water Res. Ass. AWRA, 34(3), 677-686.

Salim, I., Miller, C., and Howard, J. (1996). "Sorption isothermsequential extraction analysis of heavy metal retention in landfill liners." Soil Sci. Soc. Am. J., 60(1), 107-114.

Tinjum, J. M., Benson, C. H., and Blotz, L. R. (1997). "Soil-water characteristic curves for compacted clays." J. Geotech. Geoenviron. Eng., 123(11), 1060-1069.

Van Genuchten, M. T. (1980). "A closed form equation for predicting the hydraulic conductivity of unsaturated soils." Soil Sci. Soc. Am. J., 44, 892-898.

Van Genuchten, M., Leij, F., and Yates, S. (1991). "The RETC code quantifying the hydraulic functions of unsaturated soils." Rep. No. EPA/600/2-91/065, U.S. EPA, Office of Research and Development, Washington, D.C. 